\title{
Research and Teaching Practice on Practical English Writing in Higher Vocational Colleges
}

\author{
Li Wang $^{1}$ \\ ${ }^{1}$ Heilongjiang Tourism Vocational College, Heilongjiang, China \\ Correspondence: Li Wang, Heilongjiang Tourism Vocational College, Heilongjiang 150086, China. E-mail: \\ lyxcbwl@126.com
}

Received: January 13, 2012

Accepted: February 23, $2012 \quad$ Published: May 1, 2012

doi:10.5539/ass.v8n6p244

URL: http://dx.doi.org/10.5539/ass.v8n6p244

\begin{abstract}
This article focuses on the theoretical research and practical teaching in training and improving students' ability of practical writing in higher vocational colleges through analyzing present curricular status of writing courses. It clarifies the idea of teaching reformation and finds out a series of teaching methods possessing practical significance. It also makes a reference to the teaching reformation of practical writing courses in higher vocational colleges.
\end{abstract}

Keywords: higher vocational college students, practical writing, research, practice

\section{Introduction}

It is universally believed that the ability of practical writing is a must in modern society. According to the statistics, there is no economically developed country that does not pay attention to the cultivation of college students' practical writing ability. For example, 123 majors have set up the courses related to practical writing knowledge and skills in the United States. Harvard University, Columbia University, Dartmouth College, New York State University and George Mason University, which are world famous universities under The Ivy League, have listed writing class and analytical reasoning class (to teach practical writing mainly) into "core curriculum" rather than compulsory curriculum.

Along with an era of prevalence of higher education and China's entrance into WTO, the ability of language expression is increasingly required. To write a practical paper associated with one's own vocation has become a necessary task.

With the popularization and the application of practical writing in our country, writing ability is considered as one of the essential measures in justifying one's qualification on various occasions such as in the national civil service exam, the recruitment of leaders and members in public institutions, and the employment of members in private enterprises and talent market. What's more, practical writing ability, as an important skill, not only has become a modern symbol for cultivated individuals, also has become one of general and indispensable capacities for modern higher vocational college students.

However, the reality in practical writing classes in higher vocational colleges is not as optimistic as expected. The development of teaching practical writing is restricted by some problems, which negatively affect the improvement of students' ability. In terms of which approaches can be applied to solve these problems, the author has carried out a series of necessary research, exploration and practice.

\section{Research on the Present Situation of Practical Writing in Higher Vocational Colleges}

\subsection{The Value of Practical Writing as an Independent Discipline Is Insufficiently Recognized and Practical} Writing Courses Are Mainly Set up for Students of Arts

From the result of investigation in four southern universities in China as well as questionnaires in four Heilongjiang vocational colleges, although it is acknowledged that practical writing courses can enhance students' ability, only two colleges among all the eight colleges and universities open this course towards all the majors; the remaining six open selective courses towards majors related to arts. The six colleges and universities have not completely realized such an extensive and scientific role the practical courses play in setting up a discipline. It could be biased to think this discipline is essential for students of arts only. 


\subsection{The Semester Duration of Learning Practical Writing Courses Is too Short and There Are Not Enough Innovative Teaching Materials}

According to the survey among the eight colleges, five schools consider practical writing courses compulsory and three schools selective; in respect of the semester duration, five colleges set up practical writing course for only one semester and three schools open the course for two semesters, nevertheless with limited class hours. Training practical writing ability is a pretty slow process, requiring scientific guidance and long-term accumulation. Obviously, it could be far from achieving a satisfying effect just through a few hours' teaching.

From the aspect of teaching materials, the majority of colleges and universities are still using general textbooks; few colleges can really catch up the demand to cultivate specialized talents according to their own future occupational characteristics. Because these teaching materials are used too widely, most of them are confined to the original university teaching model and emphasize on the integrality as a system, whereas they ignore analysis of various cases during practical application and lack individual guidance in writing practice. It probably leads to the ineffective application in the reality, which is not ideal teaching effect of course. So it is expected that school-based curriculum teaching materials could bring forth the new through the old.

\subsection{The Demand to Master Writing Skills Is Urgent and the Attention Should Be Paid to What Is Truly Needed}

The author has analyzed the data of 178 samples among 500 questionnaires at random. The analysis shows that 64. $6 \%$ students are interested in practical writing courses and $57.3 \%$ want to improve it as soon as possible. Among these $57.3 \%$ students, $24.2 \%$ think it is because they want a better writing mark and $67.4 \%$ think they may need this skill in their future jobs. When students are asked what kind of practical paper they are most eager to master, $48.3 \%$ and $25.3 \%$ students choose the graduation thesis, and resumes \& cover letters respectively; when they are asked about the reasons for lack of writing skills, $52.8 \%$ of the students think that they lack the necessary training. It is noticeable from the above numbers that most students need and want to master writing skills. Although they want a quick success and want it simply for a job or a mark, it could also be a learning motivation for them. We can take advantage of this to make practice writing effective in the process of teaching.

\section{Analysis of Defects of Practical Writing Courses in Higher Vocational Colleges}

\subsection{Universities and Colleges Do Not Pay Sufficient Attention and Writing Courses Are Not Scientifically Set Up}

Practical writing courses have been included in the compulsive courses in higher vocational colleges, but they are not in the important position for higher vocational colleges for a long time. Schools are complaining about and sighing over the poor writing ability of college students while they are reducing the class hours. Once practical writing courses are set up on the school's curriculum, they will be in a dispensable position. Sometimes writing courses have to give way to professional courses; sometimes when curriculum schedule is tight, writing courses can be easily cut off. Sometimes when curriculum courses are insufficient, practical writing courses will be used to fill up. This can be proved by the research in all the eight institutions. In the past, for the majors such as tourism, hotel management, application of language, practical writing courses were usually set up for two semesters. In contrast, in recent years due to more class hours for professional courses, writing classes have been squeezed out from these professional courses and most of them are no longer on the schedule. Even if a few of them have to be set up in several particular majors, they are compressed within just one semester and less than 60 hours.

As to how many semesters for writing courses, most schools simply think writing is no more than a foundational course and belongs to liberal arts. It is enough for them to set up the writing courses in the first semester. Most do not take it into account that the acquisition of the ability of practical writing is a complex and comprehensive process based on a great amount of writing knowledge and professional knowledge. Since the majority of higher vocational students go directly into the colleges after their graduation from high schools, they just master some textbook knowledge and their knowledge about the society is narrow and shallow. Lack of necessary social experience, social knowledge as well as professional knowledge directly influences their thinking and learning. Hence if the curriculum is too advanced, it will not only make troubles for teachers, also give rise to confusion and difficulty for students. For example, in the class for administrative documents, some students have no common sense about social organizations. They cannot tell the difference from parties, politics and National People's Congress and they do not know about the names of functional departments of the government or their duties. These problems are both simple and complex. If they are not understood, teachers can hardly continue the course. This point could also be proved by the research in Shanghai Institute of Tourism, Shanghai Business College, Zhejiang Tourism College and Zhejiang Vocational College of Commerce. Among all these schools, Shanghai Commercial College and Zhejiang Tourism College have made a relevant correction according to the actual situation. 


\subsection{Students Are Eager for Quick Success and Instant Benefit and They Care More about Their Professional Courses Rather than the Basic Ones}

Although students are sure that writing ability is important in practical work, they consider professional courses more important than other foundational ones. Because writing exams, unlike computer, English and some other subjects' exams, are not entitled to occupational qualification certificates, which are one of the essential conditions of getting a job. Students devote too much energy into preparation for passing certain exams with occupational qualification certificates and do not pay attention to learning and training writing skills. Besides this, the majority of higher vocational students do not have their professional orientations in the first place and they lack learning motivations. All these mentioned above contribute to their temporary enthusiasm when they start to learn writing skills, but once they have learned for a period of time, they will discover teaching method is too single and unchangeable, coupled with their own inadequacy of basic knowledge and their lack of long-term constant and repeated writing exercise, and they will fear and escape from this difficult task.

\subsection{Teaching Materials Are Difficult to Adapt to the Need of High Vocational Education}

Although in recent years a large number of books named "Higher Vocational Practical Writing" have been published as major teaching materials, it is hardly to find any practical innovative teaching materials. Most textbooks can not break away from the stereotype of writing courses in the secondary school, with out-of-date models, concepts, language characteristics, requirements for writing style and format taking up most part of the book and with no specific and recent examples. What's more, the majority of contents are not selected from actual needs of higher vocational students and lack scientific, practical and flexible training exercises. The publication and application of such teaching materials could not fully play their role, so schools are supposed to cooperate with some professional press companies to make a change about this.

\subsection{Teachers Focus on Teaching Lectures Instead of Guiding Students' Practice}

Since the majority of colleges and universities set up writing courses for only one semester, subject to time limit, teachers have no time to do more than simply talking about writing style and format. As a result, teachers could probably ignore the analysis of examples or the practical application of methods and skills. It turns out to be that students can perfectly memorize writing format Because of no enough guidance, writing style is merely an ambiguous term for students; their expression is not appropriate and their language sense is not strong. Consequently, once they are faced with actual writing assignment, they do not know how to do it and tend to use their own knowledge and former habits of literary expression to write a paper, which makes the article neither fish nor fowl and hard to be comprehended.

\section{Teaching Practice to Cultivate and Improve Students' Ability of Practical Writing}

\subsection{Design the Teaching Plans Scientifically and Stimulate Students' Interest and Motivation in Learning}

As Einstein said "Interest is the best teacher to us." If we want to make students interested in learning, we need the scientific teaching design that can stimulate their interest and motivation.

In the research and practice, on the one hand, we are to take advantage of analyzing cases and models to make courses active. As we know the introduction part in the book is full of theories that are too abstract to be understood, we can quote a large number of successful cases and failure cases as examples, such as some graduates getting their ideal jobs with well-organized practical writing papers and some graduates losing their job opportunities due to not standard resumes or cover letters. Only through others' personal cases can they make sure how important practical writing is. Students need to know practical writing skills can not be ignored when they first contact practical writing courses; thus they can accept the teaching method better. In this teaching method, a few basic skills have to be cultivated in the first place. Subsequently different types of practical writing will be mentioned.

On the other hand, there is another good method in which we should break fixed teaching plans. Students can propose what content they would like to learn within a specific writing task. Teachers can make flexible teaching plans with variable sections of knowledge that can be put together in the class corresponding to students' need. The flexible and practical teaching plans should be proposed at different time considering different needs from different stages. It will finally come true that teachers are able to teach what students want to learn and give students knowledge for their own sake.

There is the third method. Teachers establish a mechanism of competition in the class. With combination of both writing and oral training, the interest in learning will be reinforced. For example, when teaching the lessons concerning competition speech, tour guide speech, welcome speech and farewell speech, teachers can arrange a contest as the practice. Teachers can divide students into groups to compete against one another. In the competition, students are all well-prepared, full of emotion and want to fight for their honor. Students as "audiences" also play their role in judging and marking. The atmosphere of this activity can be lively and active and the teaching effect can be positive and favorable. 


\subsection{Break through the Bound of Traditional Teaching Method and Create a Learning Atmosphere with Enthusiasm}

It takes time to improve the ability of practical writing. The traditional teaching practical writing involves three steps: writing theory --- example analysis --- composition. On most occasions after a few courses the students will find them dull and boring, so it is difficult to arouse students' interest and enthusiasm. In research and in practice, we found if we want students to gain some interest and joy from learning practical writing, we need to make them learn in the use and use in learning and finally make them acquire real skills. Therefore, we use simulative methods comprehensively in the teaching practice in order to intimate and create a variety of "practical exercises" situation and we let students participate in practice and training and encourage them to write independently.

One way is to use modern teaching media and multimedia classroom. We take advantage of PowerPoint to provide a large number of sample essays and cases in the classroom. Through appreciating good samples and making their own comments or conclusions and correcting mistakes and errors in certain samples after reading thoroughly, the students can not only easily comprehend the knowledge in textbooks, but also exercise skills of appreciation and evaluation. They can take them as references for their papers as well. For instance, when giving a lecture on "to make up an advertisement", we can use audio or video materials and use multimedia courseware to play the advertisement, the world's most creative Philippines' "ten dangers", and we will teach students what a huge benefit can be brought to a country from one single advertisement. It is certain that the lecture can certainly arouse students' interest. What's more, we can display domestic and international award-winning advertisements and make students detect the amazing part on their own. After appreciating and judging advertisements, students can further and better understand the theory of this type of writing and the ways of breaking through people's fixed minds. This will definitely have a favorable effect on teaching.

The second way is to provide a good learning atmosphere and to simulate practice drills, finally to reinforce practical writing ability in reality. For instance, in the chapter "documents writing", like dealing with a particular business, accident treatment and reporting the circumstance, teachers design the related work situation and appoint two students as a group to figure it out and scheme out work plans. In order to design a circumstance of recruitment, teachers let students write their own cover letters and resumes. Take the chapter "etiquette" as another example. Teachers suppose a specific festival occasion and make the students deliver a speech in the class; another example can be seen in chapter "tour guide speech", teachers arrange a traveling occasion, and let students play and exchange the roles of tour guides and tourists in the scene and give different speeches and the judgments. All these activities can arouse students' interest as well as exercise and strengthen students' sense of language, language expression as well as ability of summarizing and abstract thinking. They all aim at establishing the foundation of students' writing ability.

The third way is to use case analysis widely and to introduce the students' papers as samples when students learn to write specific type. Thus we can encourage students to give their own analysis and judgment, to talk about advantages and disadvantages and to use them for references.

The fourth way is to encourage students to get involved in social investigation and social practice in order to write for the actual needs, such as encouraging students to participate the school's "National Day's Writing Campaign", "January 29 speech competition" and supporting more students to participate in speech contexts held by the school and advocating students to write for the college newspaper and website, and organizing students to participate in other social activities as volunteers. Other examples can be seen as teachers give lessons of how to write the investigation report. According to different majors, teachers choose different investigation subjects, guide students to develop the investigation outline and design the questionnaire. Teachers company them in the process of social survey, and supervise students to complete the final investigation report. Teachers will remark and grade their assignments and give extra points to those students with active and outstanding performance during the whole social investigation. The activity can reinforce skills of practical writing and enrich students' social experience.

4.3 We Should Introduce New Teaching Methods like Task-Driven and Project-orientated Theories and Emphasize Students-oriented Idea

Firstly, weaken "to teach" and highlight "to guide". The student-oriented idea cannot be overemphasized, which means encouraging students with the methods of showing, leading and guiding.

Secondly, intensify the idea of "self-determination, exploration and cooperation" in the process of teaching.

Thirdly, change the teaching methods from "focusing on teaching" to "focusing on writing coupled with guidance". The primary aim is to improve the students' ability of practical writing. For example, before teaching each chapter, we will use the project-oriented method to assign students a learning task or problem. We teach students the knowledge with the related problems, and then give them one or two cases to read, discuss, analyze, 
compare and find out the key knowledge and sum up the knowledge on their own. Teachers guide the students how to analyze and summarize writing essential knowledge and make some corrections if necessary. After class, according to different kinds of writing tasks, teachers create new circumstances, name the title of the tasks and assign students to imitate good writing samples. This approach allows students to drive their action with the task or the project, to complete the task or the project with the power of action, to find out questions during writing and to be willing to challenge the task.

\subsection{We Should Introduce Standards of Skill Assessment and Reform Teaching Materials and Assessment Mechanism}

The characteristics of higher vocational education lie in that higher vocational colleges have to be professional, comprehensive and practical. Our teaching and assessment standards have to be consistent with these characteristics. The conclusions are drawn from the research:

One of these is that we should develop and publish school-based teaching materials with the characteristics and requirements of vocational education. We should take the standards of the industry and the occupation for reference and break through original traditionally-stylized pattern of teaching materials. We should integrate writing knowledge required in the occupation, and add both general types and professional types of writing forms into the sections. What's more, we should choose the vivid samples chosen from students' daily life and increase the proportion of training exercise in the textbook with more flexible and diverse forms, such as analysis and comments on sample cases, discussion in groups, training extensive knowledge, situational training and so on. All these can make teaching more scientific and more adaptable to the need.

The other conclusion is that we should introduce the form and standards of China's ZHC exam (an exam to certify the proficiency of Chinese language) into teaching materials. Also we should improve our teaching outline and reform the examination mechanism. We should encourage students to participate in ZHC exams, and link the test score to the final grade of practical writing courses. For the students with advanced certificate of ZXC exam, they will be granted with a pass of writing examination without even attending the test. For the students obtaining intermediate or beginning certificates, they will be given 50 or 30 extra marks and the final grade of writing courses will be given coupled with usual attendance, class performance, homework and daily exercises.

\section{Conclusion}

Through the above research, we figure out a clear idea of the reform of practical writing courses. In particular, this reform should focus on the nature and characteristics of vocational education. That is to say, we should design the goals, make the outlines, develop teaching materials, and find a breakthrough based on what is needed for the students in the society and based on their occupations in future career; we have known more about task-driven and project-orientated theories, an effective training mode for the talents. Taking the lessons from the new ideas of the reform, we have changed some teaching methods, experiment steps and we have practiced various up-to-date teaching methods in the real teaching process, such as task-driven theory, situational teaching, case analysis, cooperation theory, discussion theory and interactive games. They all lay a foundation for the further and sustainable development of the theory and practice of the reform; we figure out a clear idea in the construction of curriculum courses and in the development of teaching materials. That is to say, we should enrich and perfect teaching contents in constant and updated practice, should introduce the knowledge and skills required in students' future jobs and should introduce the standards and forms of China's ZHC exam, and should improve the examination mechanism, which plays an important role in cultivating and improving higher vocational students' ability of practical writing.

\section{References}

Li, Lin. (2007). With Application as the Purpose and Ability Cultivation as the Core, the Comprehensive Reform of Writing taught in Higher Vocational Colleges. The Theories.

The Ministry of Education. The Outline of Chinese Teaching in Higher Vocational Education.

The network of China's Occupational Education and Adult Education.

The Outline of China's ZHC Exam.

Wang, Qun. (2006). The Ability of Document Writing is the Combination of a lot of Abilities. Practical Writing, No. 5 .

Zhang, Yaquan. (2004). Creating a Positive Writing Atmosphere and Paying Attention to the Application of Writing and Teaching Conception. China Adult Education, (6). 